Article

\title{
Climate Change and Migration for Scandinavian Saami: A Review of Possible Impacts
}

\author{
Ilan Kelman ${ }^{1,2, *(1)}$ and Marius Warg Næss ${ }^{3}[$ \\ 1 Institute for Global Health and Institute for Risk \& Disaster Reduction, University College London, \\ London WC1E 6BT, UK; ilan_kelman@hotmail.com \\ 2 University of Agder, 4630 Kristiansand, Norway \\ 3 High North Department, Norwegian Institute for Cultural Heritage Research (NIKU), 9007 Tromsø, Norway; \\ marius.naess@niku.no \\ * Correspondence: ilan_kelman@hotmail.com
}

Received: 4 March 2019; Accepted: 27 March 2019; Published: 31 March 2019

check for updates

\begin{abstract}
Migration, especially of indigenous peoples, related to or influenced by climate change continues to gain increasing research and policy attention. Limited material remains for this topic for Scandinavia's indigenous people, the Saami. This paper contributes to filling this gap by providing a review for the Scandinavian Saami of the possible impacts of climate change on migration. Environmental influences, social influences, and a synthesis through livelihoods impacts, including for reindeer herding, is provided, followed by a discussion of Saami responses to climate change and migration mainly through a governance analysis. Overall, climate change's impacts on the Saami do not necessarily entail abandoning their traditions, livelihoods, or homes. Instead, the most significant impact is likely to be migrants moving into the Arctic to pursue resource opportunities. Working collaboratively with the Saami, policies and practices are needed to ensure that indigenous interests are respected and that indigenous needs are met.
\end{abstract}

Keywords: adaptation; climate change; displacement; indigenous; migration; Sami; Saami

\section{Background}

With the prominent and often contentious debates surrounding migration related to or influenced by climate change [1-5], it is appropriate to investigate the migration implications of climate change for all indigenous peoples. The Saami are the only indigenous people from Scandinavia-covering Finland, Norway, and Sweden-yet perhaps because they live in comparatively affluent countries, they have received limited attention with regards to climate change and migration. This paper contributes to filling this gap by providing a review for the Scandinavian Saami of the possible impacts of climate change on migration.

\subsection{Saami in Scandinavia}

Today, the Saami number approximately 50,000-100,000, although no formal censuses based on ethnicity exist. This means that defining who is Saami for statistical purposes is not always straightforward and often refers to those either speaking or having ancestors who spoke the Saami language. Norway, for example, collects geographically delineated statistics pertaining to a "Saami area". This geographic area is designated as the area covered by the Saami Parliament subsidy schemes for business development, yet the statistics do not differentiate between Saami and non-Saami in the area. Approximately 50\%-60\% of the Saami live in Norway, 30\%-40\% in Sweden, and $10 \%$ in Finland, living principally although not exclusively in the northern parts. Under $4 \%$ of Saami live in Russia, in the northwest region, but this paper focuses on Scandinavia due to similarities in governance, 
affluence, and culture amongst the three countries of Norway, Sweden, and Finland in comparison to Russia. Saami are a minority in most Scandinavian communities where they live.

Saami are frequently associated with reindeer husbandry as a livelihood, especially when tourism promotes "Saami culture" [6,7]. Only approximately $10 \%$ of Saami are currently actively involved in it [8], although reindeer husbandry dominates the literature on Saami and climate change. Reindeer herders have been nomadic, relying on their herds for food (meat and dairy), fur, and transport and for supplying those products to others in the region. Although it is difficult to pinpoint accurately the origin of reindeer husbandry as a pastoral livelihood, it developed at least 400 years ago [9] and probably evolved from a hunting culture based on wild reindeer. Reindeer husbandry has undergone a modernization process resulting in a blend of livelihoods, with traditional reindeer herding still being followed by Saami who might also be studying for a $\mathrm{PhD}$ or have other town-based livelihoods. Reindeer herders are now less likely to live with their herds as much as they did in earlier times, instead travelling from their permanent homes for herding purposes.

Other traditional livelihoods for the Saami include fishing, sealing, livestock rearing and trapping, and farming [10,11], with some groups being termed 'Sea Saami' or 'Coastal Saami'. Naturally, all Saami groups interacted and traded with each other and with non-Saami, further supplementing livelihoods. Today, tourism-based livelihoods are becoming increasingly popular [6,7], although, due to the overall dearth of statistics on the numbers of Saami, data is scarce on the extent to which tourism generates income or livelihoods by Saami and whether such income relates to Saami culture or not. In fact, there is no overall registration of Saami livelihoods-apart from reindeer herding, since that is defined by law as being an exclusively Saami livelihood in Norway and Sweden, again indicating why much of the discussion ends up examining what is known about reindeer herding.

Consequently, Saami are not a homogenous group. Examples of differences are (i) the languages and cultures of Norway, Sweden, Finland, and Russia, (ii) various base livelihoods, and (iii) contrasting expressions of Saami heritage and culture, embracing the full range along the spectrum from having no interest to continued public displays while identifying oneself as Saami only.

\subsection{Migration}

According to Scandinavian censuses, northern Scandinavia has been experiencing significant levels of outmigration in recent decades. Young people often leave the region to seek education, larger settlements, or more varied livelihoods. Migration is often initially seen as temporary-for example, for university or independent travel—but may become longer-term or permanent because the migrants prefer other locations or because their partners or families do not wish to live in the north. Migration within the region also occurs, with people from one Scandinavian settlement easily moving to another for family or livelihood reasons, irrespective of national boundaries (Scandinavians are permitted to live and work in other Scandinavian countries).

Migration has long been a way of life in Scandinavia's northern latitudes since the Saami reindeer herders have been nomadic or semi-nomadic for centuries at least [12]. As well, non-Saami have long migrated into the region. For instance, Harstad, Norway, a small northern community, has an office for the petroleum company Statoil, with many staff not originally from the region. Jokkmokk, Sweden on the Arctic Circle holds an annual winter market, generating employment for people from the region and for people who move into the region. Norway settles many refugees and asylum seekers above the Arctic Circle as part of a dispersal policy to support underpopulated regions and to avoid the ghettoization of refugees and asylum-seekers in larger centers in the south. In Norway, aside from the refugees and asylum seekers, national policy [13] has supported people living throughout the country by providing financial incentives and supporting public services.

Such policies have affected the migratory lifestyles of reindeer herders in Norway. During the 1970s, most reindeer herders in Norway had moved into modern houses in central areas in the northernmost county of Finnmark due to official policies such as the 1958 and 1969 housing programs that made modern houses affordable for herders. The policy mandating nine years of 
compulsory schooling for children also made it impossible for whole families to live close to their herd year-round [9]. These policies made it possible for reindeer herders to attain a standard of living in Norway similar to others around the country [9] which consequently changed their migratory lifestyle. Nevertheless, some herders in Norway continue to undertake large scale migrations with their herds from summer and coastal pastures to winter and inland pastures, a journey covering up to $\approx 200 \mathrm{~km}$. Mobility is thus still important for Saami herders, but artificial boundaries such as private property, roads, and railways can inhibit traditional needs and routes.

Some policies support reindeer herd migration. In 2009, Norway and Sweden signed a new cross-border grazing agreement covering 24 grazing areas that Swedish herders can use in Norway and 16 grazing areas that Norwegian herders can use in Sweden, as well as recognizing common grazing areas on both sides of the border [14,15]. In 2010, Swedish herds comprising 42,000 reindeer had grazing rights in Troms County while Swedish herds comprising 77,538 reindeer had grazing rights in Nordland and Nord-Trøndelag Counties. Swedish herds normally graze on the Norwegian side during summer, while Norwegian herds normally graze on the Swedish side during winter. Finland has closed its borders to reindeer herds, with the Norway-Finland border marked by fences to prevent cross-border grazing. On the Finland-Sweden border, rivers and lakes form a clear boundary between grazing areas. Reindeer can swim and many have calving areas on lake islands but moving the herds across the border is not permitted.

\subsection{Climate Change}

Climate change impacts are being seen in northern latitudes mainly through [16-21]:

1. Increased warming rates as distance from the coast increases.

2. Higher warming rates in winter compared to summer.

3. Increased precipitation, especially during winter. Due to rising temperatures, snowfall might decrease in some locations even if winter precipitation increases.

4. Increased storminess and more powerful wave action, augmenting coastal erosion, even while the frequency of some Arctic storms might decrease.

5. Decreasing extent and duration of snow cover and sea ice, with the eventual possibility of an ice-free Arctic Ocean in the summer.

6. Melting permafrost.

7. Increased acidity and decreased salinity of marine environments.

8. Global sea level rise on the order of $1-2 \mathrm{~m}$ at minimum by 2100 with some local variations. Within Scandinavia, absolute sea-level rise is somewhat balanced by post-ice age rebound (isostatic uplift) in which the weight of the ice age's glaciers pushed the land down so far that the land is still rising following the glacial melting. If ice sheets collapse, principally in Greenland or Antarctica, then absolute sea-level rise could be dozens of meters over the coming centuries.

\section{Effects of Climate Change on Migration}

Within international research covering the effects of climate change on migration, one fundamental debate $[22,23]$ is often articulated as balancing (i) migration as adaptation to climate change and (ii) migration as a failure to adapt to climate change. That is, migration might be partly a voluntary mechanism to deal with climate change and might partly indicate that climate change has not been dealt with, so migration is forced, all within the multitude of other factors continually affecting migration.

Within these wider contexts, three different influences are used here to provide a review of how climate change affects Saami migration. The section on "environmental influences" discusses how the changing environment will directly impact migration. This is followed by a discussion of "social influences" which analyses how climate change affects social structures, in turn impacting migration. Finally, the "livelihoods" section examines the relationship between these environmental and social influences in terms of livelihoods and migration. 


\subsection{Environmental Influences}

During spring, summer, and autumn, reindeer pastures tend to be in mountain areas [9]. With climate change projected to increase precipitation across Scandinavia year-round, biological productivity might increase in the spring, fall, and summer. Any increase in productivity could be tempered by more ground saturation and higher humidity, suggesting the possibility for more mold, fungus, insects, and invasive species. As detailed micro-scale studies are not available, exploration of the impact of climate change on reindeer's spring, summer, and autumn food is speculative, particularly given the many interacting factors.

The most important diet for reindeer during the winter is ground lichens, which are commonly found in relatively dry continental areas [9]. The rapidly shifting warm and cold periods during the winter resulting from climate change, coupled with a year-round increase in precipitation intensity, is projected to result in increased frequency of wet weather, deep snow, and ice crust formation, conditions that have been shown to have negative consequences for reindeer [24]. The capacity of winter grazing areas tends to determine the maximum possible reindeer herd size which suggests that climate change affecting winter conditions could be a factor in reducing maximum viable herd sizes.

Rees et al. [25] argue that climate change impacts are likely to inhibit reindeer husbandry livelihoods in Norway and Sweden while having a neutral impact in Finland. The main factors for these impacts are the changing vegetation distribution due to the changing climate, notably, winter temperature and winds. Nevertheless, Rees et al. [25] suggest that the effect of these changes is expected to be relatively small and well within the range of previous experience of reindeer herders dealing with climate variability. Yet almost all climate models predict future winter climatic conditions to be more variable than today for most reindeer husbandry areas suggesting that adaptation measures would still be needed, with reindeer herders in Finland indicating that climate change will bring both advantages and disadvantages for reindeer in winter [26]. Human migration impacts are likely to be limited to small changes in migration patterns by the reindeer herders, because non-climate factors are much more important in influencing decisions about investments in reindeer herding and migration patterns.

Climate change projections are especially challenging because both reindeer and herders interact with climate through indirect and complex pathways involving their food, predators, and habitats [27]. Predators include the lynx (Lynx lynx), wolverine (Gulo gulo), brown bear (Ursus arctos), wolf (Canis lupus), and golden eagle (Aquila chryaetos) with ever-changing compensation schemes-for reindeer killed by predators and other dangers such as avalanches and trains-influencing herder behavior. The impacts of climate change on predators could be multi-faceted, although it is not clear that these impacts would be significant compared to impacts from efforts to manage reindeer, predators, herders, and their interactions [28-30]. Both non-reindeer food for reindeer predators and predators' ranges could either increase or decrease. Weaker reindeer are more susceptible to predation, which could be a major factor in the winter as the reindeer are expected to need to forage longer and harder under climate change. Tracking human-reindeer-predator conflicts is not easy to compare with climate change impacts because changes occur in reindeer numbers, how the herders fill out forms requesting compensation, and the number of documented kills compared to the number of claims for kills [29,31].

Additionally, many factors other than climate influence predators, including policies and social decisions [32]. In Sweden, land use changes have been identified alongside climate change as changing reindeer's winter foraging [33], making it hard to decouple climate change's impacts. The Government of Sweden also introduced a licensed wolf hunt for anyone in 2010 and 2011 but was then forced to withdraw it under pressure from domestic environmentalists and the European Commission. The wolf issue is as contentious in Finland. People living in areas inhabited by wolves are becoming increasingly irritated by the animals while those not living in wolf areas support wolf conservation measures [34]. Consequently, wolf management regimes undergo sudden changes [35-37] which could obscure any climate links. 
Aside from reindeer herding, climate change will impact coastal Saami livelihoods. Climate change is projected to influence fish stocks in the Barents and Norwegian Seas while likely making more northern waters suitable for fish farming [38,39]. Depending on how the increased fish stocks are managed, fishing livelihoods could draw people into the region for livelihoods and recreation. That is, in-migration related to fishing livelihoods could increase under climate change.

Inland freshwater ecosystems are also affected by climate change, such as Sorvari et al. [40] implicating climate change as influencing diatoms in lakes in northern Finland. Kullman [41] identifies the tree line rising in altitude in Swedish mountains, again due to climate change. Melting permafrost will be one of the biggest ecosystem changes across northern Scandinavia. All these ecosystem shifts represent influences, amongst many others, on migration-related decisions of Saami, but none are well-studied to connect specific, and combinations of, ecosystem changes with migration-related decisions.

\subsection{Social Influences}

Social structures in Scandinavia will be affected by climate change, consequently impacting migration decisions. Indigenous activities such as farming, fishing, and reindeer herding have a strong basis of traditional knowledge. This knowledge includes environmental variabilities and trends, with immense variation in the region across time scales. As Scandinavia's climate shifts into a new regime - a regime which has not been experienced there since human habitation-the relevance of traditional knowledge for future operational decision-making is likely to decrease.

Consequently, traditional knowledge becomes less of an anchor for the Saami to their northern environments and to their traditional livelihoods, although it remains relevant in in supporting community structures and coherence. But many indigenous peoples remain in their communities because their knowledge helps them to pursue traditional livelihoods and to make sense of the environment around them as part of their identity. If the environment changes beyond the scope of their knowledge, there might be less incentive to stay in an unfamiliar environment. This increasing disconnect between indigenous people's knowledge and environmental changes is now being documented for the Saami while social influences inhibit the use of migration to respond to climate and other environmental variations $[25,27,33,42]$. In all three Scandinavian countries, the trend has been towards privatizing land, putting up fences or other barriers, redistributing and fragmenting pastures, and changing land use away from traditional livelihoods. As a consequence, while environmental variability is predicted to increase with climate change, the herders' ability to adapt is reduced including through traditional migration-related approaches.

Mining exploration promoted by the national governments-for minerals such as gold, copper, and diamonds-has long been a source of conflict with Saami interests [11]. It has detrimentally impacted mobility as an adaptation strategy by taking away grazing land and by interfering in migration routes [43].

Forestry is another major area of conflict over land use. Carina and Keskitalo [44] use a case study of Gällivare in northern Sweden, exploring how climate change is expected to exacerbate conflicts over the use of the forests for logging, reindeer husbandry, and winter tourism. Mining emerges as being a concern in this area as well, with Saami complaining that so many mining-related applications are being made that they cannot keep up with them, such as determining their impacts and whether or not to oppose them. Moreover, all such conflicts require time, resources, and energy to deal with. Even when the resolution is satisfactory to the Saami, the conflict resolution process itself may be so draining and unsettling that Saami are discouraged from continuing to pursue their pre-conflict livelihoods. The process might also affect the communities' perception of how they will be treated in the future regarding land rights, water rights (particularly for hydroelectricity), forestry, and mineral extraction.

Saami in Finland have also experienced conflicts related to forestry and mining. Meanwhile, migration from the south into Finland's Arctic has increased substantially in order to take advantage of logging livelihoods, yet the logging harms the lichen which reindeer eat. 
Another social influence is the increased infrastructure maintenance expected in Scandinavia due to climate change. As permafrost melts and the ground experiences less freezing, infrastructure built on the assumption of more stable footings may require retrofitting. With coastal wave energy expected to increase, not just as a result of storms but also due to less sea ice, coastal infrastructure will be subject to a long-term rise in the battering experienced from the sea. Overall, under climate change, infrastructure in Scandinavia is expected to undergo more damage from the physical force of waves, coastal erosion, and salt [45].

With higher overall air temperature, more transitions between freezing and non-freezing temperatures are expected, resulting in more freeze/thaw switches. When water freezes to ice, its volume expands. Saturated ground that freezes and thaws experiences heave and subsidence alternately, undermining roads, railways, power lines, and other infrastructure. The more freeze/thaw transitions experienced, the more often infrastructure might need to be repaired. The same situation is witnessed in masonry buildings where small amounts of rainwater or dew infiltrate the bricks, blocks, and mortar. When this is followed by freezing and expansion, cracks and flaking result. Haugen and Mattson [45] further describe the chemical processes leading to increased salt crystallization in buildings due to climate change and the resulting damage. The infrastructure damage caused by freeze/thaw transitions is in addition to the increased expected damage from mold and fungus emerging from increased air humidity and ground saturation.

It is hard to determine whether or not the changes to infrastructure resulting from climate change will influence migration. Would the increased maintenance costs and damage be an impetus for the Saami to seek livelihoods elsewhere? Or would more opportunities for maintenance-related livelihoods draw Saami into these livelihoods so that they stay in the Arctic while drawing people into northern Scandinavian?

The overall lesson is that indigenous understanding of and connection to the environment is undermined when climate change affects the environment so much that current knowledge has limited applicability. This situation does not prevent the knowledge being used as a starting point for developing partnerships with others, provided that what is and is not applicable is accepted. Nonetheless, many will find adaptation challenging when their knowledge-related anchor is much less relevant than before for interpreting the environment around them. This is one factor amongst many in their migration decisions - and in the migration decisions of others potentially moving to northern Scandinavia to pursue livelihoods.

\subsection{Synthesis: Livelihoods Impacts}

This analysis of the environmental and social influences of climate change on Saami migration in northern Scandinavia suggests that climate change itself will have limited impact on migration and is not likely to directly cause displacement. Instead, social and governance structures are influencing livelihoods in such a way that adaptation options are becoming limited.

In particular, the increased emphasis on resource extraction, due to climate change making northern Scandinavia more accessible to these activities, will bring major changes to Saami areas of Scandinavia. On the land, minerals mining is the main draw, with significant exploration currently underway while exploitation of forest resources is also significant. Offshore refers to Norway only, because it is the only Scandinavian country with a coastline above the Arctic Circle. The focus here is petroleum (oil and gas). Even where exploration and development occur far offshore, in or beyond the Exclusive Economic Zone, livelihoods on land are influenced due to the movement of offshore workers; the need for onshore processing, storage, and transportation facilities; and the threat of spills.

The first petroleum fields north of the Arctic Circle to be developed in Scandinavia are Snøhvit (Snow White) and Goliat, each offshore from Hammerfest, Norway. The companies involved, in conjunction with the Government of Norway, state that they have been factoring in local livelihoods and interests, including supporting local suppliers and initiatives to benefit the Saami. Little independent monitoring or evaluation is completed. Resource exploration and extraction 
support in-migration to the region, from temporary workers and from those drawn to new business opportunities generated by offshore workers continually moving through the area to get to and from the facilities. These opportunities provide a local economic boost which, if allocated for such, could help in maintaining Saami traditions. The potential also exists that Saami would be drawn to employment opportunities in the petroleum industry_leaving behind traditional hunting, fishing, and herding livelihoods or using non-traditional employment to supplement traditional livelihoods-but not migrating out of the region.

One major difference between the development of offshore and onshore resources is access to and impacts on land. If Saami are denied their traditional lands or are denied mobility, then the options for maintaining their traditional livelihoods will be severely diminished, possibly encouraging migration elsewhere in the Arctic or outside of the Arctic. In February 2019, the Government of Norway approved a copper mine in Kvalsund in northern Norway to which Saami reindeer herders and fishers had objected on the basis of pollution, disruption, and reducing access to their land.

The increased dominance of outside cultures and interests in the Saami areas of Scandinavia is expected to influence migration decisions in different ways. The increasing presence of outsiders in northern Scandinavia opens possibilities for those who wish to explore new opportunities in another region as well as potential for migration through marriage. No assumption should be made regarding the net influence of these factors on migration. The stereotypical and first-order assumption is that people in northern Scandinavia, including the Saami, go south for education, jobs, or marriage-consequently losing their roots. This happens, but many cases exist of southerners marrying Saami or non-Saami northern locals and then moving north—or simply choosing the northern land and lifestyle. Similarly, education in the south and exposure to non-northern cultures can strengthen ties to one's land and traditions, convincing Saami to return north.

A key impact of climate change is that it will draw far more outsiders and far more money into northern Scandinavia than before, providing both opportunities and distractions for Saami seeking to maintain traditional ways within a modern setting. The main consequence on migration and Saami livelihoods is not so much migration out from the north, such as abandoning traditional livelihoods because of climate change impacts, but migration into the north from non-Saami seeking to pursue livelihoods there. No migration outcome is certain but is likely to depend on how well the changes are managed internally.

\section{Saami Responses to Climate Change and Migration}

The Saami have sought to work with other indigenous groups on promoting their rights and interests in the context of climate change, such as through the United Nations Permanent Forum on Indigenous Issues and the Saami parliaments. Saami views, however, are far from homogenous. The Saami have disagreements amongst and within groups. For example, Korsmo [43] details how one group of reindeer herders in Sweden broke off from the plans for creating the Saami Parliament there in order to form its own association. There are sometimes differences in views between northern and southern Saami, as well as exclusion of Saami from certain groups or exclusion from being Saami of people who might consider themselves as Saami [46,47]. Disagreements regarding managing change also occur between Saami who herd reindeer and those who do not, as well as between larger and smaller herders.

Many reindeer herders have been proactive in terms of aiming to develop and implement climate change adaptation activities, such as in Finland [48], Sweden [42] and Norway [49]. Reindeer herders study for Masters and $\mathrm{PhD}$ degrees, further reinforcing the need to use different knowledge types for adaptation while keeping Saami youth in the north by combining traditional and other livelihoods. Many other scientific research projects led by or involving Saami exist regarding climate change adaptation, also focused on reindeer herders [50-53].

One main conclusion is that, in comparison to the impacts of management regimes for reindeer herding, the effect of near-term climate change only on reindeer husbandry is expected to be relatively 
small and within the range of the previous experience. Over the longer-term, much depends on what actions are taken regarding stopping climate change or adapting to it. That is, it seems to be the policies put in place to manage reindeer husbandry, and not climate change per se, that might influence reindeer herder migration, especially in that limiting mobility can reduce the ability to respond flexibly to climate change impacts. This conclusion is in line with most studies on climate change and displacement, that (with some potential exceptions such as heat waves and sea-level rise), it is not climate change per se causing migration, but social and governance factors inhibiting adaptation that lead to migration [1,2,4,5,54].

Climate change further sits within the context of the perceived need for strong, almost militant, Saami advocacy due to the history of the three Scandinavian national governments ignoring indigenous interests, pursuing assimilation programs and forced displacement, and avoiding acknowledgement of indigenous rights. As one of many examples, Mustonen et al. [55] provide a history of Finland's forced displacement of Saami for hydroelectric development. Similar processes occurred in Norway, where the damming of the Alta-Kautokeino watercourse above the Arctic Circle galvanized large protests and brought Saami rights to the forefront of national politics [56]. Over the past generation, the three governments have fully accepted the principles behind Saami indigenousness and the Saami as a people. In practice, disputes and differences of opinion persist with respect to interpreting and exercising Saami rights.

With climate change making northern Scandinavia more accessible, or perceived to be more accessible, to those from outside the region, continual conflict resolution will be needed, especially for reindeer herders since their migration patterns are most likely to be interfered with. In Norway, the recent history of Saami reindeer husbandry can be summarized as being influenced by increasing government subsidies and regulations regarding the meat market coupled with increased sedentarization, the use of newer technology, and trying to make reindeer herders and their representatives fully accountable for herd management decisions [9,57-59]. Government of Norway laws and policies typically focused on using economic and ecological data without extensive links to the cultural identity of Saami herders. Although the Saami own their herds, the rangelands are owned and administered by the Government of Norway, aiming for rationalization, formalization, and efficiency using the implementation mechanism of co-management between the herders and the formal institutions. In many parts of northern Norway, half of the income generated from reindeer herding can be from government support and compensation, providing some incentive to remain as herders. One consequence of this long-term, top-down government involvement has been larger herd sizes $[9,60]$.

Even with climate change as a background over the past few decades, reindeer husbandry in the three countries has experienced far greater changes-resulting from increasing hands-on management-which are not necessarily negative, but which must be acknowledged within the context of migration decisions $[9,32,33,61,62]$ :

1. Practices which decrease contact between people and animals.

2. A monetary rather than subsistence economy.

3. Sedentarization, namely settling in towns.

4. Reindeer husbandry as an occupation rather than as a way of life.

5. The use of modern technology, namely transportation and communications.

6. Increased reliance on government support and control, e.g., limiting the number of animals and recruiting reindeer herders.

7. Changing policies for dealing with predators.

These changes need to be viewed in the context of government-Saami relations beyond reindeer herding. Until later in the twentieth century, the Swedish government pursued a 'phase-out' policy, by supporting Saami land rights and traditional livelihoods to some degree while making it difficult for those rights and livelihoods to be passed down to future generations [47]. Many Saami who fished 
inland were forced from their homes along rivers due to the construction of dams and reservoirs [47]. In the late 1980's, proposals to give Saami significant control over land exploitation decisions in pasture areas were denied by the national parliament which opted instead for mandatory consultation with Saami but not mandatory implementation of Saami recommendations [47]. Consequently, logging could be pursued on pasture land without Saami approval.

In an attempt to redress these past difficulties, in 2009, Sweden passed a bill [63] stated as supporting Saami autonomy, language, and culture. The United Nations criticized the bill, stating that “Over the past ten years, Swedish policy has been based not on the Sámis' status as an indigenous people in Sweden but, at best, on the Sámis as a national minority. In Sweden, insufficient steps have been taken to ensure Sámi participation as required by international conventions"[64]. The Government of Sweden [65] disagreed, suggesting that the areas in Sweden where Saami can be accepted as an official language are being expanded while the funds given to minorities are being increased.

If these promises would be fulfilled over the long-term, they might contribute to overcoming earlier concerns about how the Saami have been treated, such as a 1981 Swedish Supreme Court ruling that the Saami do not own the land that they use for livelihoods, but instead have only a strong right to use that land [43]. Korsmo [47] details some cases of Swedish Saami taking the government to court at the European level regarding Saami rights and losing because Swedish law did not fully support indigenous rights. The updated Swedish legislation is meant to overcome some of these concerns, but no conclusions can yet be drawn regarding the legislation's impact, since the legislation has not yet been fully tested in court.

For Finland, Josefsen [8] discusses the provisions in the constitution and the current laws governing the Saami, highlighting in particular that "contrary to what is the case in both Sweden and Norway, the authorities are obliged to negotiate with the Saami Parliament regarding all important decisions that either directly or indirectly may affect the Saami's status as an indigenous people". Implementation has been less successful according to Josefsen [8] who claims that Finland's national authorities have few skills or knowledge to properly follow the legislation.

Neither Sweden nor Finland has ratified ILO Convention 169 Indigenous and Tribal Peoples Convention, 1989, whereas in 1990 Norway was the first country to do so. In fact, Saami rights to the land are strong in Norway, especially in the northernmost county of Finnmark. Based on the Finnmark Act [66], a legal entity called Finnmarkeiendom (Finnmark ownership) owns and governs the county's resources and land. Its board comprises three members selected by the Finnmark County government and three members selected by the Norwegian Saami Parliament. It has established a commission which is currently mapping existing users' and owners' rights based on long-term use. Some claim that the Finnmark Act gives the Saami special rights, although that is not the legal intention. Instead, the intention is to give all inhabitants of Finnmark equal rights to the land, water, and resources, irrespective of ethnicity. Finnmarkeiendom's work does not regulate reindeer herding, despite Finnmarkeiendom owning the land, because reindeer herding is regulated by other Norwegian laws and another government department.

The issue is not just about resource extraction with or without Saami consent, but is also about full and fair consultation, plus the perception thereof; namely, that due process is followed, and that Saami accept that due process has been followed. Similarly, perceptions that resource income is being applied for Saami benefit, and that decisions about resource income are being made in a consultative fashion, help to ensure that everyone in northern Scandinavia gains from the resource extraction expected as a result of climate change, meaning that migration out of the region would be by choice rather than being forced due to discrimination or lack of livelihoods. But the Saami and non-Saami in northern Scandinavia are clear that resource access, on land and in the sea, does not necessarily mean resource extraction. That is, other environmental uses and community values must be considered in making resource management decisions-not just the access that climate change is projected to bring.

If the Saami are not fully involved in decision-making, then the migration implications are multi-faceted, not because of climate change per se, but because of how climate change is being 
(mis)managed through resource extraction. Without access to grazing areas, and the flexibility needed as grazing areas change under climate change, little incentive exists for Saami to continue reindeer husbandry. If Saami culture and livelihoods are eroded in other ways, such as limited support for their language and pollution of lakes and rivers, then living in the region might be less attractive. These influences could lead to Saami migration out of the north as a result of the knock-on effects of the way in which climate change is addressed and the way in which governments interact with the Saami.

\section{Conclusions and Future Directions}

Saami migration related to or influenced by climate change is not an inevitable outcome for northern Scandinavia. It will be, and is, feasible to continue living in northern Scandinavian without major problems, as long as social support structures and governance regimes recognize the challenges and opportunities of the Arctic changing and, particularly, the difficulties that traditional Saami livelihoods face. Nonetheless, climate change, social support structures, and governance regimes have the potential to influence people's migration-related decisions. Three overarching recommendations are suggested from this review to permit Saami to have more control over their migration-related decisions in the context of climate change.

First, short-term action with long-term perspectives is needed now. Climate change is occurring, and will continue to occur, faster in higher latitudes than in other regions. The reindeer-herding Saami see a need for action as soon as possible due to climate change's consequences for their reindeer herding livelihoods. Simultaneously, they stress the need for long-term perspectives when planning for climate change in the context of all the other, often linked, challenges and opportunities, such as mining, petroleum, the alleged lure of the south for them, and the alleged lure of the north for others. Examples of actions as investment opportunities are upgrading current (often decaying) infrastructure, generating self-sustaining livelihoods, and developing social structures that, irrespective of climate change, maintain Saami values and traditions within the context of modern technology and society. Thus, climate change adaptation could be used as an opportunity to improve living conditions for Saami and to sustain Saami livelihoods in the context of all issues. That is, climate change becomes an opportunity for supporting Arctic life and livelihoods.

Second, full and fair participation of Saami in decisions affecting them should be ensured, including for migration-related topics, covering everything from reindeer mobility to people choosing to settle in or out of northern Scandinavia. Any policy or regulatory measures taken should be developed, implemented, monitored, and enforced with full and fair participation of Saami, including recognizing differences of opinion amongst different Saami groups. Measures relevant across the three Scandinavian countries-and preferably also including Russia-might be particularly effective. Strengthening the powers of the Saami parliaments might or might not assist in such actions but should be considered without neglecting changes at the national and local levels to ensure that Saami interests are heard in national parliaments and in local jurisdictions. Non-Saami must also be included in consultations.

Third, changing demographics of northern Scandinavia need to be recognized and addressed, especially with regards to temporary migrants. As a principle, Saami usually do not typically oppose others moving into northern Scandinavia, permanently or temporarily. Nor are the Saami opposed to the principle of resource exploitation, whether that be petroleum, mining, forestry, fish, hydroelectricity, or others. They do tend to oppose (i) decisions being made without Saami input and (ii) outsiders taking over Arctic locations and resources without respecting those already living there. Beyond full and fair participation and decision-making power, measures include better links between the Saami and resource exploitation projects; ensuring that non-Saami understand Saami perspectives and vice versa; and using resource wealth to support Saami culture, language, and livelihoods.

Within these three points, much of the discussion here and in the literature focuses on reindeer herding, yet there are major gaps in understanding the migration-related decisions of non-reindeer 
herding Saami. Unlike reindeer herders, other Saami have not extensively used seasonal migration as part of their livelihoods. More work is needed to understand the migration perspectives of non-reindeer-herding Saami. Because they are not tied to reindeer, are non-reindeer herding Saami more flexible regarding migration? Or because they are tied to their fixed homes, are they less flexible regarding migration?

Climate change is already occurring and is unlikely to be curtailed soon, meaning that the effects must be dealt with. This does not mean indigenous peoples such as Saami abandoning their traditions, livelihoods, or homes. Instead, climate change impacts on indigenous people in northern Scandinavia can be reduced, including migration remaining as a choice rather than being forced. To achieve this approach means working collaboratively to ensure that indigenous interests are respected and that indigenous needs are met without precluding the involvement of others in the region and without being overwhelmed by climate change's detrimental impacts.

Author Contributions: Conceptualization, I.K. and M.W.N.; Formal analysis, I.K. and M.W.N.; Writing-original draft, I.K. and M.W.N.; Writing-review and editing, I.K. and M.W.N.

Funding: The initial report on which this work is based was funded by the Brookings Institute, Washington, D.C., U.S.A. Further work was supported by the Research Council of Norway (grant numbers 204174 and 240280).

Conflicts of Interest: The funders commissioned the topic and the focus, but had no role in the design of the paper, in the writing of the manuscript, or in the decision to publish the results.

\section{References}

1. Bettini, G. Climate Barbarians at the Gate? A Critique of Apocalyptic Narratives on 'Climate Refugees'. Geoforum 2013, 45, 63-72. [CrossRef]

2. Brzoska, M.; Fröhlich, C. Climate Change, Migration and Violent Conflict: Vulnerabilities, Pathways and Adaptation Strategies. Mig. Dev. 2016, 5, 190-210. [CrossRef]

3. Hartmann, B. Rethinking Climate Refugees and Climate Conflict: Rhetoric, Reality and the Politics of Policy Discourse. J. Int. Dev. 2010, 22, 233-246. [CrossRef]

4. Klepp, S.; Herbeck, J. The politics of environmental migration and climate justice in the Pacific region. J. Hum. Rights Environ. 2016, 7, 54-73. [CrossRef]

5. Nicholson, C. Climate Change and the Politics of Causal Reasoning: The Case of Climate Change and Migration. Geogr. J. 2014, 180, 151-160. [CrossRef]

6. Leu, T.C.; Müller, D.K. Maintaining inherited occupations in changing times: The role of tourism among reindeer herders in northern Sweden. Pol. Geogr. 2016, 39, 40-57. [CrossRef]

7. Leu, T.C.; Eriksson, M.; Müller, D.K. More than just a job: Exploring the meanings of tourism work among Indigenous Sámi tourist entrepreneurs. J. Sustain. Tour. 2018, 26, 1468-1482. [CrossRef]

8. Josefsen, E. The Saami and the National Parliaments: Channels for Political Influence; Inter-Parliamentary Union and United Nations Development Programme: Geneva, Switzerland, 2010.

9. Riseth, J.Å.; Vatn, A. Modernization and Pasture Degradation: A Comparative Study of Two Sàmi Reindeer Pasture Regions in Norway. Land Econ. 2009, 85, 87-106. [CrossRef]

10. Broadbent, N.D.; Edvinger, B.W. Sacred Sites, Settlements and Place-Names: Ancient Saami Landscapes in Northern Coastal Sweden. In Landscape and Culture in Northern Eurasia; Jordan, P., Ed.; Routledge: London, UK, 2011; pp. 315-337.

11. Koivurova, T.; Masloboev, V.; Hossain, K.; Nygaard, V.; Petrétei, A.; Vinogradova, S. Legal Protection of Sami Traditional Livelihoods from the Adverse Impacts of Mining: A Comparison of the Level of Protection Enjoyed by Sami in Their Four Home States. Arct. Rev. Law Pol. 2015, 6, 11-51. [CrossRef]

12. Broadbent, N.D. Lapps and Labyrinths: Saami Prehistory, Colonization, and Cultural Resilience; Smithsonian Institute: Washington, DC, USA, 2013.

13. Government of Norway. St.meld. nr. 25: Lokal Vekstkraft og Framtidstru. Om Distrikts-og Regionalpolitikken; Government of Norway: Oslo, Norway, 2009.

14. Governments of Norway and Sweden. Konvensjon Mellom Norge og Sverige om Grenseover Skridende Reindrift; Governments of Norway and Sweden: Oslo, Norway; Stockholm, Sweden, 2009. 
15. Governments of Norway and Sweden. Områdeprotokoll til Konvensjon Mellom Norge og Sverige om Grenseoverskridende Reindrift; Governments of Norway and Sweden: Oslo, Norway; Stockholm, Sweden, 2009.

16. ACIA. Arctic Climate Impacts Assessment; Cambridge University Press: Cambridge, UK, 2005.

17. AMAP. Snow, Water, Ice and Permafrost in the Arctic (SWIPA); Arctic Monitoring and Assessment Programme: Oslo, Norway, 2017.

18. AMAP. AMAP Assessment 2018: Arctic Ocean Acidification; Arctic Monitoring and Assessment Programme: Tromsø, Norway, 2018.

19. ARR. Arctic Resilience Report; Arctic Council: Stockholm, Sweden, 2016.

20. CAFF. Arctic Biodiversity Assessment; Conservation of Arctic Flora and Fauna: Akureyri, Iceland, 2013.

21. IPCC. IPCC Fifth Assessment Report; IPCC (Intergovernmental Panel on Climate Change): Geneva, Switzerland, 2013-2014.

22. Felli, R.; Castree, N. Neoliberalising adaptation to environmental change: Foresight or foreclosure? Environ. Plan. A 2012, 44, 1-4. [CrossRef]

23. Stojanov, R. (Ed.) Migration as Adaptation? Population Dynamics in the Age of Climate Variability; Global Change Research Centre, Academy of the Sciences of the Czech Republic: Brno, Czech Republic, 2014.

24. Solberg, E.J.; Jordhoy, P.; Strand, O.; Aanes, R.; Loison, A.; Saether, B.E.; Linnell, J.D.C. Effects of density-dependence and climate on the dynamics of a Svalbard reindeer population. Ecography 2001, 24, 441-451. [CrossRef]

25. Rees, W.G.; Stammler, F.M.; Danks, F.S.; Vitebsky, P. Vulnerability of European reindeer husbandry to global change. Clim. Chang. 2008, 87, 199-217. [CrossRef]

26. Turunen, M.T.; Rasmus, S.; Bavay, M.; Ruosteenoja, K.; Heiskanen, J. Coping with difficult weather and snow conditions: Reindeer herders' views on climate change impacts and coping strategies. Clim. Risk Manag. 2016, 11, 15-36. [CrossRef]

27. Pape, R.; Löffler, J. Climate Change, Land Use Conflicts, Predation and Ecological Degradation as Challenges for Reindeer Husbandry in Northern Europe: What do We Really Know After Half a Century of Research? Ambio 2012, 41, 421-434. [CrossRef] [PubMed]

28. Bulte, E.H.; Rondeau, D. Why compensating wildlife damages may be bad for conservation. J. Wildl. Manag. 2005, 69, 14-19. [CrossRef]

29. Næss, M.W.; Bårdsen, B.-J.; Pedersen, E.; Tveraa, T. Pastoral herding strategies and governmental management objectives: Predation compensation as a risk buffering strategy in the Saami reindeer husbandry. Hum. Ecol. 2011, 39, 489-508. [CrossRef]

30. Thomas, M.G.; Bårdsen, B.-J.; Næss, M.W. The narrow gap between norms and cooperative behaviour in a reindeer herding community. R. Soc. Open Sci. 2018, 5. [CrossRef] [PubMed]

31. Schwerdtner, K.; Gruber, B. A conceptual framework for damage compensation schemes. Biol. Conserv. 2007, 134, 354-360. [CrossRef]

32. Riseth, J.Å.; Tømmervik, H.; Bjerke, J.W. 175 years of adaptation: North Scandinavian Sámi reindeer herding between government policies and winter climate variability (1835-2010). J. For. Econ. 2016, 24, 186-204. [CrossRef]

33. Uboni, A.; Blochel, A.; Kodnik, D.; Moen, J. Modelling occurrence and status of mat-forming lichens in boreal forests to assess the past and current quality of reindeer winter pastures. Ecol. Ind. 2019, 96, 99-106. [CrossRef]

34. Bisi, J.; Kurki, S. The Wolf Debate in Finland; Ruralia Institute, University of Helsinki: Helsinki, Finland, 2008.

35. Ericsson, G.; Heberlein, T.A.; Karlsson, J.; Bjärvall, A.; Lundvall, A. Support for hunting as a means of wolf Canis lupus population control in Sweden. Wildl. Biol. 2004, 10, 269-276. [CrossRef]

36. Naess, A.; Mysterud, I. Philosophy of Wolf Policies I: General Principles and Preliminary Exploration of Selected Norms. Conserv. Biol. 1987, 1, 22-34. [CrossRef]

37. Skogen, K. The Persistence of an Economic Paradigm: Unintended Consequences in Norwegian Wolf Management. Hum. Dimens. Wildl. 2015, 20, 317-322. [CrossRef]

38. Hansen, C.; Drinkwater, K.F.; Jähkel, A.; Fulton, E.A.; Gorton, R.; Skern-Mauritzen, M. Sensitivity of the Norwegian and Barents Sea Atlantis end-to-end ecosystem model to parameter perturbations of key species. PLoS ONE 2019, 14, e0210419. [CrossRef] [PubMed]

39. Stenevika, E.K.; Sundby, S. Impacts of climate change on commercial fish stocks in Norwegian waters. Mar. Pol. 2007, 31, 19-31. [CrossRef] 
40. Sorvari, S.; Korhola, A.; Thompson, R. Lake diatom response to recent Arctic warming in Finnish Lapland. Glob. Chang. Biol. 2002, 8, 171-181. [CrossRef]

41. Kullman, L. 20th Century Climate Warming and Tree-limit Rise in the Southern Scandes of Sweden. Ambio 2001, 30, 72-80. [CrossRef] [PubMed]

42. Löf, A. Examining limits and barriers to climate change adaptation in an Indigenous reindeer herding community. Clim. Dev. 2013, 5, 328-339. [CrossRef]

43. Korsmo, F. Claiming Territory: The Saami Assemblies as Ethno-Political Institutions. Pol. Geogr. 1996, 20, 163-179. [CrossRef]

44. Carina, E.; Keskitalo, H. Climate Change, Vulnerability and Adaptive Capacity in a Multi-use Forest Municipality in Northern Sweden. In Community Adaptation and Vulnerability in Arctic Regions; Hovelsrud, G.K., Smit, B., Eds.; Springer: Berlin/Heidelberg, Germany, 2009; pp. 285-311.

45. Haugen, A.; Mattsson, J. Preparations for climate change's influences on cultural heritage. Int. J. Clim. Change Strat. Manag. 2011, 3, 386-401. [CrossRef]

46. Axelsson, P.; Sköld, P. Indigenous Populations and Vulnerability. Characterizing Vulnerability in a Sami Context. Ann. Dém. Hist. 2006, 1, 115-132. [CrossRef]

47. Korsmo, F. Swedish Policy and Saami Rights. North. Rev. 1993, 11, 32-55.

48. Vuojala-Magga, T.; Turunen, M.; Ryyppö, T.; Tennberg, M. Resonance Strategies of Sámi Reindeer Herders in Northernmost Finland during Climatically Extreme Years. Arctic 2011, 64, 227-241. [CrossRef]

49. Plummer, R.; Baird, J. Adaptive Co-Management for Climate Change Adaptation: Considerations for the Barents Region. Sustainability 2013, 5, 629-642. [CrossRef]

50. Eira, I.M.G.; Oskal, A.; Hanssen-Bauer, I.; Mathiesen, S.D. Snow cover and the loss of traditional indigenous knowledge. Nat. Clim. Chang. 2018, 8, 928-931. [CrossRef]

51. Oskal, A.; Turi, J.M.; Mathiesen, S.D.; Burgess, P. EALÁT: Reindeer Herders Voice: Reindeer Herding, Traditional Knowledge and Adaptation to Climate Change and Loss of Grazing Lands; International Centre for Reindeer Husbandry: Kautokeino/Guovdageadnu, Norway, 2009.

52. Pogodaev, M.; Oskal, A. Youth: The Future of Reindeer Herding Peoples; Sustainable Development Working Group, Arctic Council: Tromsø, Norway, 2015.

53. Turi, J.M. Native reindeer herders' priorities for research. Pol. Res. 2000, 19, 131-133. [CrossRef]

54. Bedford, R.; Hugo, G. Population Movement in the Pacific: A Perspective on Future Prospects; Department of Labour: Wellington, New Zealand, 2012.

55. Mustonen, M.; Mustonen, T.; Aikio, A.; Aikio, P. Drowning Reindeer, Drowning Homes: Indigenous Sámi And Hydroelectricity Development in Sompio, Finland; Snowchange: Vaasa, Finland, 2010.

56. Briggs, C.M. Science, local knowledge and exclusionary practices: Lessons from the Alta Dam case. Norsk Geogr. Tids. Nor. J. Geogr. 2006, 60, 149-160. [CrossRef]

57. Marin, A.F. Confined and Sustainable? A Critique of Recent Pastoral Policy for Reindeer Herding in Finnmark, Northern Norway. Nomadic Peoples 2006, 10, 209-232. [CrossRef]

58. Riseth, J.Å. Sámi reindeer herd managers: Why do they stay in a low-profit business? Br. Food J. 2006, 108, 541-559. [CrossRef]

59. Ulvevadet, B. Management of reindeer husbandry in Norway-Power-sharing and participation. Rangifer 2008, 28, 53-78. [CrossRef]

60. Næss, M.W.; Bårdsen, B.-J. Environmental Stochasticity and Long-Term Livestock Viability-Herd-Accumulation as a Risk Reducing Strategy. Hum. Ecol. 2010, 38, 3-17. [CrossRef]

61. Beach, H. Pastoralism Politics in Sweden: Protecting the Environment and Designing the Herder. In Negotiating Nature: Culture, Power, and Environmental Argument; Hornborg, A., Pálsson, G., Eds.; Lund University Press: Lund, Sweden, 2000; pp. 179-211.

62. Paine, R. Herds of the Tundra: A Portrait of Saami Reindeer Pastoralism; Smithsonian Institution Press: Washington, DC, USA, 1994.

63. Government of Sweden. From Recognition to Empowerment-The Government's Strategy for the National Minorities (no. 2008/2009:158); Government of Sweden: Stockholm, Sweden, 2009.

64. OHCHR. The Sámi indigenous people in Sweden and the Right to Participate in Decision-Making; The Office of the High Commissioner for Human Rights (OHCRH): Geneva, Switzerland, 2010. 
65. Government of Sweden. Minority Rights are Strengthened. Ministry for Integration and Gender Equality; Government of Sweden: Stockholm, Sweden, 2010.

66. Government of Norway. Act of 17 June 2005 No. 85 Relating to Legal Relations and Management of Land and Natural Resources in the County of Finnmark (Finnmark Act); Government of Norway: Oslo, Norway, 2005.

(C) 2019 by the authors. Licensee MDPI, Basel, Switzerland. This article is an open access article distributed under the terms and conditions of the Creative Commons Attribution (CC BY) license (http:/ / creativecommons.org/licenses/by/4.0/). 